\title{
Thiobarbiturate and barbiturate salts of Pefloxacin drug: growth, structure, thermal stability and IR-spectra
}

Nicolay N. Golovnev ${ }^{a}$, Maxim S. Molokeev ${ }^{b, c, a^{*}}$, Maxim K. Lesnikov $^{a}$, Irina V. Sterkhova ${ }^{d}$,

Victor V. Atuchin ${ }^{e, f, g, h, i}$

${ }^{a}$ Siberian Federal University, 79 Svobodny Ave., Krasnoyarsk 660041, Russia

${ }^{b}$ Laboratory of Crystal Physics, Kirensky Institute of Physics, Federal Research Center KSC SB RAS, bld. 38 Akademgorodok 50, Krasnoyarsk 660036, Russia

${ }^{c}$ Department of Physics, Far Eastern State Transport University, 47 Seryshev Str., Khabarovsk 680021, Russia

${ }^{d}$ Laboratory of Physical Chemistry, Irkutsk Favorsky Institute of Chemistry, SB RAS, 1

Favorsky, Irkutsk 664033, Russia

${ }^{e}$ Laboratory of Optical Materials and Structures, Institute of Semiconductor Physics, SB RAS,

Novosibirsk 630090, Russia

${ }^{f}$ Functional Electronics Laboratory, Tomsk State University, Tomsk 634050, Russia

${ }^{g}$ Laboratory of Semiconductor and Dielectric Materials, Novosibirsk State University,

Novosibirsk 630090, Russia

${ }^{h}$ Institute of Chemistry, Tyumen State University, Tyumen 625003, Russia

${ }^{i}$ Laboratory of Single Crystal Growth, South Ural State University, Chelyabinsk 454080, Russia

${ }^{*}$ Corresponding author:

Maxim Molokeev

E-mail: msmolokeev@gmail.com

Laboratory of Crystal Physics, Kirensky Institute of Physics, Federal Research Center KSC SB RAS, bld. 38 Akademgorodok 50, Krasnoyarsk 660036, Russia

Tel.: +7-391-249-45-07

$\uparrow$ Electronic supplementary information (ESI) available. See DOI:xxx 


\begin{abstract}
Three new salts of pefloxacin $(\mathrm{PefH})$ with thiobarbituric $\left(\mathrm{H}_{2} \mathrm{tba}\right)$ and barbituric $\left(\mathrm{H}_{2} \mathrm{ba}\right)$ acids, pefloxacinium 2-thiobarbiturate trihydrate, $\mathrm{PefH}_{2}(\mathrm{Htba}) \cdot 3 \mathrm{H}_{2} \mathrm{O} \quad(\mathbf{1})$, pefloxacinium 2thiobarbiturate, $\mathrm{PefH}_{2}(\mathrm{Htba}) \quad$ (2) and bis(pefloxacinium barbiturate) hydrate, $\left(\mathrm{PefH}_{2}\right)_{2}(\mathrm{Hba})_{2} \cdot 2.56 \mathrm{H}_{2} \mathrm{O}(3)$ are synthesized and structurally characterized by the X-ray singlecrystal diffraction. The structures of $\mathbf{1 - 3}$ contain intramolecular hydrogen bonds $\mathrm{C}-\mathrm{H}$...F, OH...O. Intermolecular hydrogen bonds $\mathrm{N}-\mathrm{H} . . . \mathrm{O}$ and $\mathrm{O}-\mathrm{H}$...O form a $2 \mathrm{D}$ plane network in 1. In 2 and $\mathbf{3}$, intermolecular hydrogen bonds $\mathrm{N}-\mathrm{H}$...O form the infinite chains. In 1-3, the $\mathrm{Htba}^{-}$and $\mathrm{Hba}^{-}$ions are connected with $\mathrm{PefH}_{2}{ }^{+}$only by one intermolecular hydrogen bond $\mathrm{N}-\mathrm{H}$... O. In 2 and 3, two $\mathrm{Htba}^{-}$and $\mathrm{Hba}^{-}$ions are connected by two hydrogen bonds $\mathrm{N}-\mathrm{H}$... O. These pairs form infinite chains. All three structures are stabilized by $\pi-\pi$ interactions of the head-to-tail type between $\mathrm{PefH}_{2}{ }^{+}$ions. Compounds $\mathbf{2}$ and $\mathbf{3}$ have been characterized by powder XRD, TG-DSC and FT-IR.
\end{abstract}

Keywords Thiobarbituric acid; barbituric acid; pefloxacin; salts; X-ray diffraction; infrared spectroscopy; thermal stability

\title{
1. Introduction
}

Fluoroquinolones $(\mathrm{FxH})$ are the broad spectrum bactericidal antibiotics and the compounds work against both Gram-positive and Gram-negative bacteria. Pefloxacin (PefH), widely used in clinical practice, is an important representative of this class (Fig. 1a) [1, 2]. It possesses moderate activity against anaerobes and Mycobactoria, to which the quinolone in general has low activity. Because of low solubility, PefH is commonly used in the form of a salt [3], for example, pefloxacinium methasulfonate, $\mathrm{PefH}_{2}\left(\mathrm{CH}_{3} \mathrm{SO}_{3}\right)$. Therefore, a further search for other pefloxacin salts with improved properties is of great practical interest. 
Barbiturates are a class of drugs, which are used as anesthetics and sleeping agents, and they are utilized for the treatment of different psychiatric disorders [4]. Barbituric and thiobarbituric acids (Fig. 1b) are the key compounds, which are applied in the synthesis of their different derivatives having an important therapeutic value [5-8]. Barbituric acid $\left(\mathrm{H}_{2}\right.$ ba) possesses specific, relatively weak acidic properties $\left(\mathrm{pK}_{\mathrm{a}}\right.$ ca. 4.03 [9]) resulting from the presence of two methylene hydrogen atoms. Thiobarbituric acid $\left(\mathrm{H}_{2} \mathrm{tba}\right)$ is a stronger acid ( $\mathrm{pK}_{\mathrm{a} 1}$ ca. 1.87 [10]), which acidic properties also results from the presence of two methylene hydrogen atoms. The existence of three polymorphs of anhydrous $\mathrm{H}_{2}$ ba and dihydrate [11-13], and six polymorphs of anhydrous thiobarbituric acid and hydrate [14] make these molecules interesting from the viewpoint of crystal engineering. They can be used as building blocks in the construction of supramolecular assemblies with distinctive properties. The possibility of non-covalent interactions ensures the rich supramolecular chemistry of $\mathrm{H}_{2}$ tba and $\mathrm{H}_{2}$ ba compounds. On the other hand, the donor-acceptor features of these acids are important for the crystal design of pharmaceuticals, molecular recognition and catalytic activity [15]. It is particularly interesting to evaluate the structure and properties of the salts containing simultaneously two representatives of different pharmaceutically-active classes, namely, fluoroquinolones and barbituric acids. The fundamental aim of the present work is to explore the solid-state pefloxacinium thiobarbiturate and pefloxacinium barbiturate structures. The molecular and supramolecular structures of fluoroquinolones with barbituric acids [16], which are currently absent in CSD, are also useful. Here, we report on the synthesis data, IR spectra and thermal stability of three salts, pefloxacinium 2-thiobarbiturate trihydrate, $\mathrm{PefH}_{2}(\mathrm{Htba}) \cdot 3 \mathrm{H}_{2} \mathrm{O} \quad$ (1), pefloxacinium 2thiobarbiturate, $\mathrm{PefH}_{2}(\mathrm{Htba})$ (2) and bis(pefloxacinium 2-thiobarbiturate) hydrate, $\left(\mathrm{PefH}_{2}\right)_{2}(\mathrm{Htba})_{2} \cdot 2.56 \mathrm{H}_{2} \mathrm{O}(3)$ 


\section{Experimental section}

\subsection{Reagents and synthesis}

Pefloxacin (CAS 70458-92-3), thiobarbituric acid (CAS 504-17-6), barbituric acid (CAS 67-527) with the a purity of $\geq 98 \%$ and pefloxacin (CAS 70458-92-3) were obtained from SigmaAldrich and used as received. Acetone as a reagent analytical grade (Acros) was used without additional purification. Compounds 1-3 were prepared by the crystallization from the aqueous solution. For the synthesis of $\mathbf{2}$, PefH $(0.6 \mathrm{mmol})$ was dissolved in water $\left(5 \mathrm{~cm}^{3}\right)$ at $80{ }^{\circ} \mathrm{C}$, then a solid $\mathrm{H}_{2}$ tba $(0.6 \mathrm{mmol})$ was added to the resulting solution under stirring and the solution was kept at $80{ }^{\circ} \mathrm{C}$ up to the total dissolution of $\mathrm{H}_{2}$ tba. The $\mathrm{pH}$ of solution was equal 4.2 (a multitest IPL-103 pH meter, Semico, Russia). Then, the solution was slowly cooled firstly down to room temperature and then down to $4{ }^{\circ} \mathrm{C}$. In $20 \mathrm{~min}$, the pale orange precipitate formed as fine rectangular crystals was filtered off, washed with acetone and dried in the air to a constant mass. The yield of powder product 2. pale orange in color, was 53\%. In the following, powder sample $\mathbf{2}$ was used for IR and TG-DSC measurements. The single crystal of $\mathbf{1}$ (golden-color prism) was occasionally grown by the continuous evaporation of the filtrate at $4{ }^{\circ} \mathrm{C}$ within 6 months. However, we could not get compound $\mathbf{1}$ at a rate sufficient for the thermal and spectroscopic measurements. The pale-yellow compound $\mathbf{3}$ was prepared with the yield of $43 \%$, by a procedure analogous to that described for the preparation of 2 , but $\mathrm{H}_{2} \mathrm{ba}(\mathrm{pH}=4.6)$ was used instead of $\mathrm{H}_{2}$ tba. The crystals of $\mathbf{2}$ and $\mathbf{3}$, suitable for single crystal X-ray diffraction analysis, were grown by the corresponding filtrate evaporation at $4{ }^{\circ} \mathrm{C}$. The optical microscopy images of crystals 2 and 3 were obtained using a Nikon Eclipse LV100 Microscope (фирма, страна ?)and they are presented in Fig. 1S. The attempts to obtain other hydrates of these compounds by the crystallization from an aqueous solution were unsuccessful.

Anal. Calc. for $\mathrm{C}_{21} \mathrm{H}_{30} \mathrm{FN}_{5} \mathrm{O}_{8} \mathrm{~S}(\mathbf{1})$ : C, 47.5; H, 5.69; N, 13.2; S, 6.03. Found: C, 48.0; H, 5.26; N, 13.6; S, 6.21\%. Anal. Calc. for $\mathrm{C}_{21} \mathrm{H}_{24} \mathrm{FN}_{5} \mathrm{O}_{5} \mathrm{~S}: \mathrm{C}, 52.8 ; \mathrm{H}, 5.07 ; \mathrm{N}, 14.7 ; \mathrm{S}, 6.72$. Found: $\mathrm{C}$, 52.5; H, 4.89; N, 14.3; S, 6.87\% (2). Anal. Calc. for $\mathrm{C}_{42} \mathrm{H}_{50} \mathrm{~F}_{2} \mathrm{~N}_{10} \mathrm{O}_{14.56}(3)$ : C, 52.2; H, 5.22; N, 14.5. Found: C, 51.8; H, 5.13; N, $14.7 \%$. 


\subsection{X-ray diffraction analysis}

The intensity patterns were collected from single crystals $\mathbf{1}, \mathbf{2}$ and $\mathbf{3}$ using the SMART APEX II and D8 Venture X-ray single crystal diffractometers (Bruker AXS, Germany) equipped with a CCD-detector, graphite monochromator and a Mo $\mathrm{K} \alpha$ radiation source. The absorption corrections were applied using the SADABS program. The structures were solved by the direct methods using package SHELXS and refined in the anisotropic approach to non-hydrogen atoms using the SHELXL program [17]. All hydrogen atoms were found via Fourier difference maps. Then, the hydrogen atoms, which are linked with $\mathrm{C}, \mathrm{N}$ atoms in the $\mathrm{Htba}^{-}, \mathrm{Hba}^{-}$and $\mathrm{PefH}^{+}$ions, were positioned geometrically as riding on their parent atoms with $d(C-H)=0.93-0.98 \AA, d(N-$ $\mathrm{H})=0.86-0.89 \AA$ depending on geometry and $\mathrm{U}_{\text {iso }}(\mathrm{H})=1.2 \mathrm{U}_{\mathrm{eq}}(\mathrm{C}, \mathrm{N})$. All hydrogen atoms of the $\mathrm{H}_{2} \mathrm{O}$ molecules and one $\mathrm{H}$ atom in the $\mathrm{OH}$ group of $\mathrm{PefH}^{+}$ion were refined with bond length restraint $\mathrm{d}(\mathrm{O}-\mathrm{H})=0.9 \AA$ and $\mathrm{U}_{\mathrm{iso}}(\mathrm{H})=1.2 \mathrm{U}_{\mathrm{eq}}(\mathrm{O})$. The structure test for the presence of missing symmetry elements and possible voids was produced using the PLATON program [18]. The DIAMOND program is used for the crystal structure plotting [19].

The powder X-ray diffraction data of $\mathbf{2}$ and $\mathbf{3}$ were obtained using a diffractometer D8 ADVANCE (Bruker, Germany) equipped by a VANTEC detector with a Ni filter. The measurements were made using $\mathrm{Cu} \mathrm{K} \alpha$ radiation. The structural parameters defined by a single crystal analysis were used as a base in the powder pattern Rietveld refinement. The refinement was produced using program TOPAS 4.2 [20]. The low $R$-factors and good refinement results shown in (Fig. 2S) indicate the phase purity of powder samples $\mathbf{2}$ and $\mathbf{3}$.

\subsection{Physical measurements}

TGA was carried out on the simultaneous SDT-Q600 thermal analyzer (TA Instruments, USA) under the dynamic air atmosphere $\left(50 \mathrm{ml} / \mathrm{min}\right.$ flow rate) within $22-350{ }^{\circ} \mathrm{C}$ at the scan rate of $10{ }^{\circ} \mathrm{C} / \mathrm{min}$. The qualitative composition of the evolved gases was determined by the FT-IR 
spectrometer Nicolet380 (Thermo Scientific, USA) combined with a thermal analyzer and with the TGA/FT-IR interface (attachment for the gas phase analysis). This set up allows a simultaneous accumulation of the DTA/TG data and the released gas composition. The sample weight was $5.603 \mathrm{mg}$ for 2 and $6.302 \mathrm{mg}$ for $\mathbf{3}$. Platinum crucibles with perforated lids were used as containers. The IR absorption spectra of the compounds packed in $\mathrm{KBr}$ tablets were recorded over the range of $400-4000 \mathrm{~cm}^{-1}$ at room temperature on an FT-IR spectrometer Nicolet 6700 (Thermo Scientific, USA, SFU CEJU).

\section{Results and discussion}

\subsection{Crystal structure of (1)}

The unit cell of pefloxacinium 2-thiobarbiturate trihydrate, $\mathrm{PefH}_{2}{ }^{+}\left(\mathrm{Htba}^{-}\right) \cdot 3 \mathrm{H}_{2} \mathrm{O}$ (1), corresponds to triclinic symmetry. Space group $P-1$ was determined from the statistical analysis of reflection intensities. The main structural data are enumerated in Table 1 . The main bond lengths and valence angles are listed in Table 1S. Generally, they coincide with those given in the literature for the $\mathrm{PefH}_{2}{ }^{+}$ion [21-24] and $\mathrm{Htba}^{-}$ion [25-29].

In crystal 1, the independent part of the unit cell contains one $\mathrm{PefH}_{2}{ }^{+}$ion, one $\mathrm{Htba}^{-}$ion and three $\mathrm{H}_{2} \mathrm{O}$ molecules (Fig. 2a). There are two intramolecular hydrogen bonds $\mathrm{C}-\mathrm{H}$...F, O-H...O (Fig. 2a) and nine intermolecular hydrogen bonds $\mathrm{N}-\mathrm{H} . . \mathrm{O}, \mathrm{O}-\mathrm{H} . . . \mathrm{O}$ in the structure (Fig. 3a, Table 2S) which form a 2D plane network. This is the 5-nodal net with stoichiometry (3-c)(3c)(3-c)(4-c)(5-c) and with the vertex symbol $\left(3.5 .6 .8^{2} .9\right)\left(3.5 .6^{2} .7^{2} .8^{3} .9\right)(3.5 .6)\left(5.6^{2}\right)\left(5.8^{2}\right)$ which is new [30].

Similar to $\mathbf{1}$, the structures of pefloxacinium methanesulfonate hydrates $[22,23]$ are also stabilized by hydrogen bonds involving the terminal piperazinyl $\mathrm{N}$ atom of the pefloxacinium and an $\mathrm{O}$ atom of the methanesulfonate ion with strong $\mathrm{N}-\mathrm{H} \cdots \mathrm{O}$ interactions, and the carbonyl and carboxyl groups of $\mathrm{PefH}_{2}{ }^{+}$are also involved in a strong intramolecular $\mathrm{O}-\mathrm{H} \cdots \mathrm{O}$ hydrogen bond. In 1, two Htba ions are bound together with hydrogen bonds by means of two identical 
chains, consisting of two water molecules, with the formation of synthon $\mathrm{R}_{6}{ }^{6}$ (20). Each $\mathrm{Htba}^{-}$ ion has two such ions in the nearest environment (Fig. 3a). $\mathrm{PefH}_{2}{ }^{+}$is connected with two $\mathrm{H}_{2} \mathrm{O}$ molecules and two $\mathrm{Htba}^{-}$ions. In 1, two $\mathrm{N}$ atoms of the thiobarbiturate ion are the hydrogen bond donors and two $\mathrm{O}$ atoms from keto and carboxyl groups of the $\mathrm{PefH}_{2}{ }^{+}$cation are the acceptors. The most interesting motifs in this network are $\mathrm{R}_{3}^{3}(10), \mathrm{R}_{6}{ }^{4}(12), \mathrm{R}_{6}{ }^{5}(14)$ and $\mathrm{R}_{6}{ }^{6}(20)$ (Fig. 3a). The $\pi-\pi$ interactions between $\mathrm{Htba}^{-}$and $\mathrm{PefH}_{2}{ }^{+}$ions, and between two $\mathrm{PefH}_{2}{ }^{+}$ions (in a head-to-tail manner) stabilize the structure. Earlier, a similar packing of $\mathrm{PefH}_{2}{ }^{+}$ions was observed in the structures of $\left(\mathrm{PefH}_{2}{ }^{+}\right) \mathrm{CH}_{3} \mathrm{SO}_{3}{ }^{-} \cdot 2 \mathrm{H}_{2} \mathrm{O}$ [23] $\left(\mathrm{PefH}_{2}{ }^{+}\right) \mathrm{CH}_{3} \mathrm{SO}_{3}{ }^{-} \cdot 0.1 \mathrm{H}_{2} \mathrm{O}$ [22] and $\left(\mathrm{PefH}_{2}{ }^{+}\right)_{2} \mathrm{PtCl}_{4}{ }^{2-} \cdot 2 \mathrm{H}_{2} \mathrm{O}$ [24]. The $\pi-\pi$ interaction in $\mathbf{1}$ combines pefloxacinium cations into the pairs (Table 3S, Fig. 3Sa).

\subsection{Crystal structure of (2)}

The unit cell of $\mathrm{PefH}_{2}{ }^{+}\left(\mathrm{Htba}^{-}\right)$(2) corresponds to monoclinic symmetry. The space group $P 2{ }_{1} / c$ was determined from the statistical analysis of the reflection intensities and extinction rules. The main crystal data are shown in Table 1 . The main bond lengths and valence angles are listed in Table 1S. The structural characteristics of $\mathbf{2}$ are in a good relation with those found for $\mathbf{1}$ and those given in the literature for ions $\mathrm{PefH}_{2}{ }^{+}$[21-24] and $\mathrm{Htba}^{-}$[25-29].

The independent part of the unit cell contains one $\mathrm{PefH}_{2}{ }^{+}$ion and one $\mathrm{Htba}^{-}$ion (Fig. 2b). There are two intramolecular hydrogen bonds C-H...F, O-H...O (Fig. 2b) and three intermolecular hydrogen bonds $\mathrm{N}-\mathrm{H}$... $\mathrm{O}$ in the structure (Fig. 3b, Table 2S) which form a chain along the $a$ axis. The $\mathrm{Htba}^{-}$ion in $\mathbf{2}$ has the $\mathrm{H}$-bond direct to $\mathrm{PefH}_{2}{ }^{+}$, like that in $\mathrm{PefH}_{2}(\mathrm{Htba}) \cdot 3 \mathrm{H}_{2} \mathrm{O}(\mathbf{1})$. The number of intermolecular hydrogen bonds in compound $\mathbf{2}$ is much smaller than that in $\mathbf{1}$ due to the absence of water molecules in compound $\mathbf{2}$, which can stabilize the crystal structures with an imbalance in the number of acceptors and donors [31]. $\mathrm{PefH}_{2}{ }^{+}$has two hydrogen bond donors (carboxylic acid, $\mathrm{O}-\mathrm{H} ;\left(\mathrm{CH}_{3}\right) \mathrm{NH}^{+}$group) and six potentially strong hydrogen bond acceptors (three $\mathrm{N}$ - and three $\mathrm{O}$-atoms). $\mathrm{Htba}^{-}$ion has potentially two hydrogen bond donors (two NH groups) and five acceptors (two O-, two $\mathrm{N}$ - and one $\mathrm{S}$-atoms). In the structure of $\mathbf{2}$, an imbalance 
in the number of donors and acceptors in $\mathrm{PefH}_{2}{ }^{+}$is partly compensated by the active participation in the hydrogen bonding of $\mathrm{Htba}^{-}$ion (Fig. 3b). Structure 2 is stabilized by the intermolecular hydrogen bonds $\mathrm{N}-\mathrm{H}$... $\mathrm{O}$ between $\mathrm{Htba}^{-}$ions forming a centrosymmetric homosynton $\mathrm{R}_{2}^{2}(8)$ and $\mathrm{C}_{2}^{2}(10)$. Besides, the $\mathrm{Htba}^{-}$ions form infinite chains along the $a$-axis. Also, there are $\pi-\pi$ interactions between two rings of $\mathrm{PefH}_{2}{ }^{+}$in the structure (Table $3 \mathrm{~S}$, Fig. 3Sb). Contrary to $\mathbf{1}$, the $\mathrm{Htba}^{-}$ions in compound $\mathbf{2}$ are not involved in the $\pi-\pi$ interaction. However, the $\pi-\pi$ interactions between two $\mathrm{PefH}_{2}$ rings jointed them into the pairs in $\mathbf{2}$.

\subsection{Crystal structure of (3)}

The unit cell of $\left(\mathrm{PefH}_{2}\right)_{2}(\mathrm{Hba})_{2} \cdot 2.56 \mathrm{H}_{2} \mathrm{O}(3)$ corresponds to triclinic symmetry, and space group $P-1$ was identified for the structure. The main crystal data are shown in Table 1 . The main bond lengths and valence angles are enumerated in Table 1S.

The independent part of the unit cell contains two $\mathrm{PefH}_{2}{ }^{+}$ions, two $\mathrm{Hba}^{-}$ions, one ordered water molecule and two disordered $\mathrm{H}_{2} \mathrm{O}$ molecules with partial occupations (Fig. 2c). The occupancy sum of all $\mathrm{H}_{2} \mathrm{O}$ in the independent part of the unit cell is equal to 2.562(4). In structure 3 , the hydrogen bonding can not be analyzed in detail because the positions of $\mathrm{H}$ atoms of disordered water molecules were not found. Anyway, there are two intramolecular hydrogen bonds $\mathrm{C}-\mathrm{H} . . . \mathrm{F}$, O-H...O (Fig. 2c) , six intermolecular hydrogen bonds N-H...O (Fig. 3c) and, at least, one O$\mathrm{H}$...O bond in the structure (Table 2S), which form a chain along the $a$-axis. The hydrogen bond pattern is similar to the pattern of $\mathbf{2}$ (Fig. 3b). The dominant hydrogen bonding in $\mathbf{3}$ is the $\mathrm{N}-\mathrm{H} \cdots \mathrm{O}$ interaction, which leads to a centrosymmetric synthon $\mathrm{R}_{2}{ }^{2}(8)$ and to the formation of an infinite chain of $\mathrm{Hba}^{-}$ions. The similar infinite chains from $\mathrm{Htba}^{-}$ions were observed in $\mathbf{2}$. There are several $\pi-\pi$ interactions between two rings of $\mathrm{PefH}_{2}{ }^{+}$and $\mathrm{Hba}^{-}$(Table 3S, Fig. 3S).

\subsection{IR spectroscopy}

The IR spectra of $\mathrm{PefH}_{2}(\mathrm{Htba})(\mathbf{2})$ and $\left(\mathrm{PefH}_{2}\right)_{2}(\mathrm{Hba})_{2} \cdot 2.56 \mathrm{H}_{2} \mathrm{O}(3)$ are shown in Figure 6S. They are very difficult for the interpretation because of numerous bands in the wavenumber range 
below $1500 \mathrm{~cm}^{-1}$. In the analysis of the IR spectra, the results of earlier studies were used for comparison [32-35]. The IR spectra of $\mathbf{2}$ (Fig. 4S, curve 1) and $\mathbf{3}$ (Fig. 4S, curve 2) are significantly different from the spectra of initial reagents (PefH, $\mathrm{H}_{2}$ tba or $\mathrm{H}_{2}$ ba) and this indicates the formation of new compounds. The very broad bands in the range of $3600-3400 \mathrm{~cm}^{-1}$ can be assigned to the stretching modes of $\mathrm{NH}$ and $\mathrm{OH}$ in the $\mathrm{PefH}_{2}{ }^{+}, \mathrm{Htba}^{-}$and $\mathrm{Hba}^{-}$ions. In the region of stretching vibrations $\mathrm{C}=\mathrm{O}$ in IR spectra of $\mathrm{Hba}^{-}$ions, the band with the highest frequency lies at $1688 \mathrm{~cm}^{-1}$ [34]. In the alkaline and alkali earth metals (M) thiobarbiturates, the $\mathrm{M}-\mathrm{O}$ bond is weak and predominantly ion-dipole by nature and, therefore, one can assume that the stretching vibrations $\mathrm{C}=\mathrm{O}$, which were found in the IR spectra of these compounds, can be attributed to the uncoordinated $\mathrm{Htba}^{-}$ions. The highest frequency band $v(\mathrm{C}=\mathrm{O})$ in sodium thiobarbiturate is located at $1645 \mathrm{~cm}^{-1}$ [27] and it is located at $1630 \mathrm{~cm}^{-1}$ in potassium thiobarbiturate [36]. The band associated with $v(\mathrm{C}=\mathrm{O})$ of $\mathrm{Htba}^{-}$and $\mathrm{Hba}^{-}$ions is located noticeably below $1700 \mathrm{~cm}^{-1}$. Thus, the bands at $1716 \mathrm{~cm}^{-1}$ in 2 and at $1706 \mathrm{~cm}^{-1}$ in $\mathbf{3}$ correspond to the stretching vibration $v(\mathrm{C}=\mathrm{O})$ in $\mathrm{COOH}$ groups [35]. This proves the protonation of carboxyl group PefH and it is in agreement with X-ray single crystal structural results. The low frequency of another very strong absorption band $v(\mathrm{C}=\mathrm{O})$ at $1629 \mathrm{~cm}^{-1}$, obtained in the IR spectra of $\mathbf{2}$ and $\mathbf{3}$, can be explained by the participation of the $\mathrm{O} 2$ atom of $\mathrm{PefH}_{2}{ }^{+}$in an intramolecular hydrogen bond $\mathrm{O} 2-\mathrm{H}$...O1 (Figure $1 \mathrm{~b}, \mathrm{c}$ ) and/or it is assigned to $\mathrm{v}(\mathrm{C}=\mathrm{O})$ in $\mathrm{Htba}^{-}$and $\mathrm{Hba}^{-}$ions, respectively.

\subsection{Thermal decomposition}

According to TG curves, the mass of sample 2 remains unchanged up to $\sim 270{ }^{\circ} \mathrm{C}$ (Fig. $5 \mathrm{~S}$ ), and there are no peaks in the DSC curve below this temperature. This confirms the anhydrous nature of the compound. Compound 2 melts with the decomposition at $T>270{ }^{\circ} \mathrm{C}$. The decomposition is accompanied by an endo effect at $275.3^{\circ} \mathrm{C}$. As it is known, $\mathrm{H}_{2}$ tba melts with decomposition at $250.6^{\circ} \mathrm{C}$ [37], i.e. compound $\mathbf{2}$ is more thermally stable than $\mathrm{H}_{2}$ tba. According to the IR spectroscopic analysis of the gases evolved during thermolysis, $\mathrm{H}_{2} \mathrm{O}, \mathrm{CO}_{2}, \mathrm{SO}_{2}$ and $\mathrm{NH}_{3}$ are formed. 
Both TG and DSC curves of $\mathbf{3}$ show the two-step dehydration which is accompanied by two endo effects at $124.7^{\circ} \mathrm{C}$ and $244.1^{\circ} \mathrm{C}$ (Fig. 6S). This is confirmed by the results of IR spectroscopic analysis of evolved gases, according to which, when the sample is heated to 260 ${ }^{\circ} \mathrm{C}$, only the two-step dehydration takes place. The first stage of dehydration proceeded in the range of $60-150{ }^{\circ} \mathrm{C}$ and showed the weight loss $(\Delta \mathrm{m})$ equal to $4.1 \%$. The second dehydration stage in the range of $235-260{ }^{\circ} \mathrm{C}$ showed $\Delta \mathrm{m}=1.8 \%$. The total weight loss $(5.9 \%)$ is bigger than the weight loss calculated under the assumption of the total dehydration $\left(-2.5 \mathrm{H}_{2} \mathrm{O}\right.$, $\left.\Delta \mathrm{m}_{\text {theor }}=4.66 \%\right)$. The detected difference can be explained by the partial overlap of the second stage of dehydration with the oxidative decomposition of compound 3. Pure $\mathrm{H}_{2}$ ba melts with the decomposition at $245.0^{\circ} \mathrm{C}$ [38] and, respectively, the thermal stability of compound $\mathbf{3}$ is higher than that of $\mathrm{H}_{2}$ ba. The oxidative decomposition products are $\mathrm{H}_{2} \mathrm{O}, \mathrm{CO}_{2}, \mathrm{NH}_{3}$.

\section{Conclusions}

The crystallization of PefH with 2-thiobarbituric and barbituric acids resulted in the isolation of three new salts. Two intramolecular hydrogen bonds $\mathrm{C}-\mathrm{H} . . . \mathrm{F}, \mathrm{O}-\mathrm{H} . . . \mathrm{O}$ and intermolecular hydrogen bonds $\mathrm{N}-\mathrm{H} . . . \mathrm{O}, \mathrm{O}-\mathrm{H} . . . \mathrm{O}$ stabilize the structures of 1-3. The $\mathrm{Htba}^{-}$and $\mathrm{Hba}^{-}$ions are connected with $\mathrm{PefH}_{2}{ }^{+}$only by intermolecular hydrogen bond $\mathrm{N}-\mathrm{H} \ldots \mathrm{O}$. In 1, two $\mathrm{N}$ atoms of thiobarbiturate ion are the hydrogen bond donors and two $\mathrm{O}$ atoms of keto and carboxyl groups of the $\mathrm{PefH}_{2}{ }^{+}$cation are the acceptors. However, in 2-3, the positively charged piperazinium $\mathrm{N}$ atom in $\mathrm{PefH}_{2}{ }^{+}$is the $\mathrm{H}$-bond donor and the $\mathrm{O}$ atom from the keto group of $\mathrm{Htba}^{-}$or $\mathrm{Hba}^{-}$ions is the acceptor. The dominant hydrogen bonding in $\mathbf{2 - 3}$ appeared due to the $\mathrm{N}-\mathrm{H} \cdots \mathrm{O}$ interaction, which leads to a centrosymmetric synthon $\mathrm{R}_{2}^{2}(8)$ and the formation of infinite chains of $\mathrm{Htba}^{-}$or $\mathrm{Hba}^{-}$ions. Commonly, fluoroquinolones have potentially two strong hydrogen bond donors and 6-7 potentially strong hydrogen bond acceptors [39]. An imbalance in the donor/acceptor number in the fluoroquinolone salts can be compensated by the incorporation of water molecules into crystal lattices, as it appears in $\mathbf{1}$. The water molecules stabilize the crystal structures by forming a diverse arrangement of supramolecular heterosynthons [40]. Another way of the compensation 
of an imbalance in the donor/acceptor ratio is the inclusion of the anions capable of selfassociation in the composition of fluoroquinolone salts, for example, the $\mathrm{Htba}^{-}$or $\mathrm{Hba}^{-}$ions, as it is observed in $\mathbf{2}$ and $\mathbf{3}$. Structures 1-3 are stabilized by the $\pi-\pi$ interactions between the $\mathrm{PefH}_{2}{ }^{+}$ ions of the head-to-tail type. These interactions connect $\mathrm{PefH}_{2}{ }^{+}$ions in pairs in $\mathbf{1 - 2}$ or in the infinite chains in $\mathbf{3}$ (Table $3 \mathrm{~S}$, Fig. 2S). Also, there are the $\pi-\pi$ interactions between $\mathrm{Htba}^{-}$and

$\mathrm{PefH}_{2}{ }^{+}$ions in 1. The IR spectral data are in agreement with the X-ray single crystal diffraction analysis. The thermal stability of compounds $\mathbf{2}$ and $\mathbf{3}$ is evidently higher than that of $\mathrm{H}_{2}$ tba and $\mathrm{H}_{2}$ ba acids.

\section{Supplementary data}

The crystallographic data (excluding structure factors) for the structural analysis have been deposited with Cambridge Crystallographic Data Centre ((1) - CCDC 1537391; (2) CCDC 1537392; (3) - CCDC 1537393). The information may be obtained free of charge from The Director, CCDC, 12 Union Road, Cambridge CB2 1EZ, UK (Fax: +44(1223)336-033, Email: deposit@ccdc.cam.ac.uk, or www: www.ccdc.cam.ac.uk).

\section{Acknowledgements}

The study was carried out within the public task of the Ministry of Education and Science of the Russian Federation to the Siberian Federal University (4.7666.2017/BP) in 2017-2019. The reported study was funded by RFBR according to the research project 16-52-48010 and 17-5253031. Also, the work was supported by Act 211, Government of the Russian Federation, contract 02.A03.21.0011 and by the Ministry of Education and Science of the Russian Federation (4.1346.2017/PP). The X-ray data from single crystals were obtained with the use of the analytical equipment of the SB RAS Baikal collective Use Center and using the analytical equipment of the SB RAS Krasnoyarsk Collective Use Center. 


\section{References}

1. Padeiskaya E.N. Prevention, Diagnosis, and Pharmacotherapy of Some Infectious Diseases (Bioinform, Moscow, 2002) (in Russian)

Падейская Е.Н. Антибиотики и химиотерапия N 3-4 (2006): C.53-64(in Russian)

2. Mitsher L.A. Chem. Rev. 105 (2005) 559.

3. Zhang C.-L., Wang Y. J. Chem. Eng. Data. 53 (2008) 1295-1297.

4. Goodman L.S., Gilman A. (1970) Pharmacological Basis of Therapeutics, The MacMillan Company, London: 98-132

Laurence L. Brunton, Bruce A. Chabner, Björn C. Knollmann (2011) Pharmacological Basis of Therapeutics, $12^{\text {th }}$ edition, McGraw Hill Professional,: 1808

5. A. I. Rakhimov, S. A. Avdeev, Le Thi Doan Chang // Russ. J. General Chem., 2009, Vol. 79, No. 2, pp. 338-339.

6. Levina R.Ya., Velichko F.K. (1960) Advances in the chemistry of barbituric acids. Russ. Chem. Rev. 29(8): 437-459

7. Bojarski J.T., Mokrosz J.L., Barton H.J., Paluchowska M.H. (1985) Recent progress in barbituric acid chemistry. Adv. Heterocycl. Chem. 38: 229-297

8. Ahluwalia V.K., Aggarwal R. (1996) Chemistry of thiobarbituric acid. Proc. Ind. Nat. Sci. Acad. A 62(5): 369-413

9. Braga D., Cadoni M., Grepioni F., Maini L., Rubini K. CrystEngComm. 8 (2006) 756 10. 46.

Mendez E., Cerda M.F., Gancheff J.S., Torres J., Kremer C., Castiglioni J., Kieninger M., Ventura O.N. J. Phys. Chem. C. 2007. V. 111. N 8. P. 3369-3383.

11. T.C. Lewis, D.A. Tocher, S.L. Price, Cryst. Growth Des. 4 (2004) (5) 979-987

12. Zencirci N., Gstrein E., Langes C., Griesser U.J. Thermochim. Acta 485 (2009) 33-42. 13.

Schmidt M.U., Brüning J., Glinnemann J., Hützler M.W., Mörschel P., Ivashevskaya S.N., Streek J., Braga D., Maini L., Chierotti M.R., Gobetto R. Angew. Chem. Int. Ed. 50 (2011) 
7924-7926

14. Chierotti M.R., Ferrero L., Garino N., Gobetto R., Pellegrino L., Braga D., Grepioni F., Maini L. Chem. Eur. J. 2010. V.16. P.4347 - 4358.

15. K.T. Mahmudov, M.N. Kopylovich, A.M. Maharramov, M.M. Kurbanova, A.V. Gurbanov, A.J.L. Pombeiro, Coord. Chem. Rev. 265 (2014) 1.

16. Cambridge Structural Database, Version 5.37, Univ. of Cambridge, Cambridge, UK, 2015

17. G.M. Sheldrick, Acta Cryst. A, 2008, 64, 112-122.

18. PLATON - A Multipurpose Crystallographic Tool. Utrecht University, Utrecht, The Netherlands, 2008.

19. K. Brandenburg, M. Berndt, DIAMOND - Visual Crystal Structure Information System CRYSTAL IMPACT, Postfach 1251, D-53002 Bonn

20. Bruker AXS TOPAS V4: General profile and structure analysis software for powder diffraction data. - User’s Manual, Bruker AXS, Karlsruhe, Germany, 2008.

21. Fun H.-K, Hemamalini M., Shetty D.N., Narayana B., Eathirajan H.S. Acta Cryst. E66 (2010) o714

22. Parvez M., Arayne M.S., Sultana N., Siddiqi A.Z. Acta Cryst. C56 (2000) 910.

23.Toffoli, P., Rodier, N., Ceolin, R. \& Blain, Y. Acta Cryst. C43 (1987) 1745-1748.

24. Toffoli, P., Khodadad P., Rodier, N.. Acta Cryst. C44 (1988) 470

25. N.N. Golovnev, M.S. Molokeev, Acta Crystallogr. C69 (7) (2013) 704.

26. N.N. Golovnev, M.S. Molokeev, S.N. Vereshchagin, V.V. Atuchin, J. Coord. Chem. 66 (23) (2013) 4119.

27. N.N. Golovnev, M.S. Molokeev, S.N. Vereshchagin S.N., V.V. Atuchin, M.Y. Sidorenko, M.S. Dmitrushkov, Polyhedron 70 (1) (2014) 71.

28. N.N. Golovnev, M.S. Molokeev, Russ. J. Inorg. Chem. 59 (9) (2014) 943.

29. N.N. Golovnev, M.S. Molokeev, Russ. J. Coord. Chem. 40 (9) (2014) 564.

30. V.A. Blatov; A.P. Shevchenko; D.M. Proserpio. Crystal Growth \& Design., 14, 3576 (2014). 
31. Clarke H.D., Arora K.K., Bass H., Kavuru P., Ong T.T., Pujari T., Wojtas L., Zaworotko M.J. Cryst. Growth. Des. 10 (2010) 2152-2167.

32. N.A. Smorygo, B.A. Ivin, Khim. Geterotsikl. Soedin. 10 (1975) 1402.

33. J.T. Bojarski, J.L. Mokrosz, H.J. Barton, M.H. Paluchowska, Adv. Heterocycl. Chem. 38 (1985) 229.

34. H.C. Garcia, F.B. de Almeida, R. Diniz, M.I. Yoshida, L.F.C. de Oliveira, J. Coord. Chem. $64(2011) 1125$.

35. [Dorofeev V.L. Pharmaceutical Chemistry Journal. 38 (2004) (12) 693-697.

36. N.N. Golovnev, M.S. Molokeev, and M.Y. Belash, J. Struct. Chem., 2013, 54(3), 566-570.

37. N.N. Golovnev, M.S. Molokeev, L.S. Tarasova, V.V. Atuchin, N.I. Vladimirova._J. Mol.

Struct. 2014. V.1068. P. 216-221

38. Chierotti M.R., Gaglioti K., Gobetto R., Braga D., Grepioni F., Maini L. CrystEngComm. 2013. - 15. - P. 7598-7605.

39. I. Turel, Coord. Chem. Rev. 232 (2002) 27-47.

40. Desiraju R.J., J. Chem. Soc.. Chem. Commun. (1991) 426-428.

\section{Graphical Abstract}

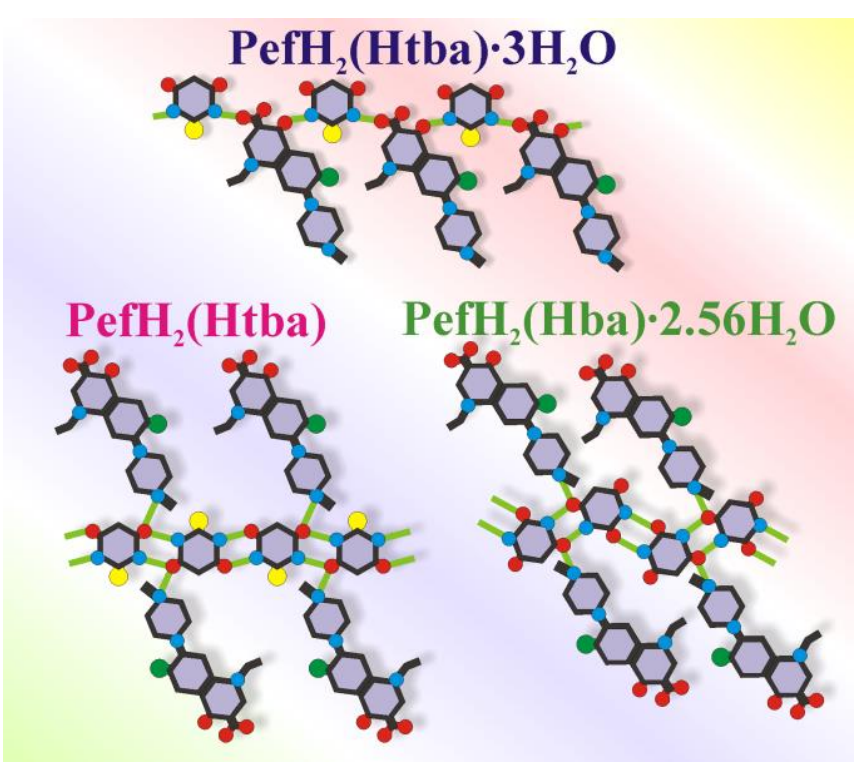


Table 1. Crystal structure parameters of 1-3

\begin{tabular}{|c|c|c|c|}
\hline Single crystal & $\mathrm{PefH}_{2}(\mathrm{Htba}) \cdot 3 \mathrm{H}_{2} \mathrm{O}(\mathbf{1})$ & $\mathrm{PefH}_{2}(\mathrm{Htba})(\mathbf{2})$ & $\left(\mathrm{PefH}_{2}\right)_{2}(\mathrm{Hba})_{2} \cdot 2.56 \mathrm{H}_{2} \mathrm{O} \quad(\mathbf{3})$ \\
\hline Moiety formula & $\mathrm{C}_{21} \mathrm{H}_{30} \mathrm{FN}_{5} \mathrm{O}_{8} \mathrm{~S}$ & $\mathrm{C}_{21} \mathrm{H}_{24} \mathrm{FN}_{5} \mathrm{O}_{5} \mathrm{~S}$ & $\mathrm{C}_{42} \mathrm{H}_{50} \mathrm{~F}_{2} \mathrm{~N}_{10} \mathrm{O}_{14.56}$ \\
\hline Dimension (mm) & $0.2 \times 0.16 \times 0.05$ & $0.20 \times 0.30 \times 0.35$ & $0.43 \times 0.20 \times 0.17$ \\
\hline Color & Pale orange & Pale yellow & Pale yellow \\
\hline Molecular weight & 531.56 & 477.51 & 965.88 \\
\hline Temperature $(\mathrm{K})$ & 150 & 150 & 296 \\
\hline Space group, $Z$ & $P-1,2$ & $P 2{ }_{1} / c$ & $P-1,2$ \\
\hline$a(\AA)$ & $8.4651(6)$ & $12.0768(9)$ & $10.3252(3)$ \\
\hline$b(\AA)$ & $9.3753(6)$ & $14.7120(11)$ & $13.8631(4)$ \\
\hline$c(\AA)$ & $15.8077(9)$ & $12.2222(9)$ & $16.9586(3)$ \\
\hline$\alpha\left(^{\mathrm{o}}\right)$ & $89.484(2)$ & 90 & $101.243(1)$ \\
\hline$\beta\left(^{(\mathrm{o})}\right.$ & $88.735(2)$ & $95.109(3)$ & $92.514(1)$ \\
\hline$\gamma\left({ }^{o}\right)$ & $78.147(2)$ & 90 & $109.471(1)$ \\
\hline$V\left(\AA^{3}\right)$ & $1227.48(14)$ & $2162.9(3)$ & $2229.1(1)$ \\
\hline$\rho_{\text {calc }}\left(\mathrm{g} / \mathrm{cm}^{3}\right)$ & 1.438 & 1.466 & 1.439 \\
\hline$\mu\left(\mathrm{mm}^{-1}\right)$ & 0.196 & 0.204 & 0.115 \\
\hline $\begin{array}{l}\text { Reflections } \\
\text { measured }\end{array}$ & 11838 & 105889 & 24769 \\
\hline $\begin{array}{l}\text { Reflections } \\
\text { independent }\end{array}$ & 5647 & 6337 & 10127 \\
\hline $\begin{array}{l}\text { Reflections with } F \\
\quad>4 \sigma(F)\end{array}$ & 3139 & 4737 & 7257 \\
\hline $2 \theta_{\max }\left({ }^{\circ}\right)$ & 55.27 & 60.16 & 55.02 \\
\hline$h, k, l$ - limits & $\begin{array}{c}-10 \leq h \leq 10 \\
-12 \leq k \leq 12 \\
-20 \leq l \leq 18\end{array}$ & $\begin{array}{c}-17 \leq h \leq 17 \\
-20 \leq k \leq 20 \\
-17 \leq l \leq 17\end{array}$ & $\begin{array}{c}-13 \leq h \leq 13 \\
-17 \leq k \leq 17 \\
-15 \leq l \leq 22\end{array}$ \\
\hline$R_{\text {int }}$ & 0.0473 & 0.0869 & 0.0278 \\
\hline $\begin{array}{l}\text { The weighed } \\
\text { refinement of } F^{2}\end{array}$ & $\begin{array}{l}w=1 /\left[\sigma^{2}\left(F_{\mathrm{o}}^{2}\right)+(0.0628\right. \\
\left.P)^{2}\right]\end{array}$ & $\begin{array}{l}w=1 /\left[\sigma^{2}\left(F_{\mathrm{o}}^{2}\right)+(0.0570 P)^{2}+\right. \\
1.4849 \mathrm{P}]\end{array}$ & $\begin{array}{l}w=1 /\left[\sigma^{2}\left(F_{\mathrm{o}}^{2}\right)+(0.1137 P)^{2}+0 .\right. \\
3971 \mathrm{P}]\end{array}$ \\
\hline $\begin{array}{l}\text { Number of } \\
\text { refinement } \\
\text { parameters }\end{array}$ & 346 & 303 & 637 \\
\hline$R 1\left[F_{\mathrm{o}}>4 \sigma\left(F_{\mathrm{o}}\right)\right]$ & 0.0523 & 0.0468 & 0.0550 \\
\hline$w R 2$ & 0.1060 & 0.1116 & 0.1704 \\
\hline Goof & 0.905 & 1.060 & 1.039 \\
\hline$\Delta \rho_{\max }\left(\mathrm{e} / \AA^{3}\right)$ & 0.416 & 0.893 & 0.626 \\
\hline$\Delta \rho_{\min }\left(\mathrm{e} / \AA^{3}\right)$ & -0.287 & -0.328 & -0.373 \\
\hline$(\Delta / \sigma)_{\max }$ & 0.001 & 0.001 & 0.001 \\
\hline
\end{tabular}


<smiles>CCn1cc(C(=O)O)c(=O)c2cc(F)c(N3CCN(C)CC3)cc21</smiles>

a)

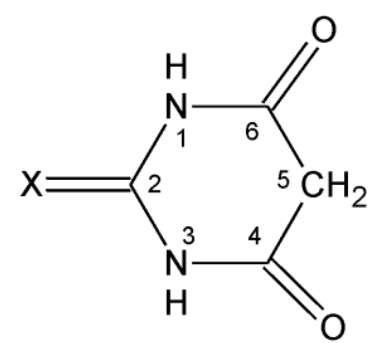

$\mathrm{X}=\mathrm{S}, \mathrm{O}$

b)

Figure 1. Schemes of pefloxacin (a) and barbituric acids (b): $\mathrm{X}=\mathrm{O}$ in $\mathrm{H}_{2}$ ba and $\mathrm{X}=\mathrm{S}$ in $\mathrm{H}_{2}$ tba. 


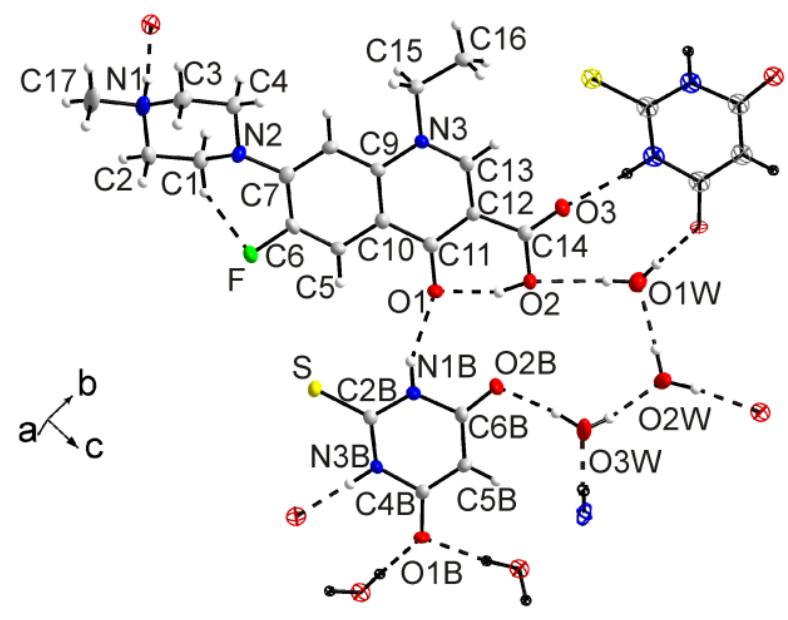

a)

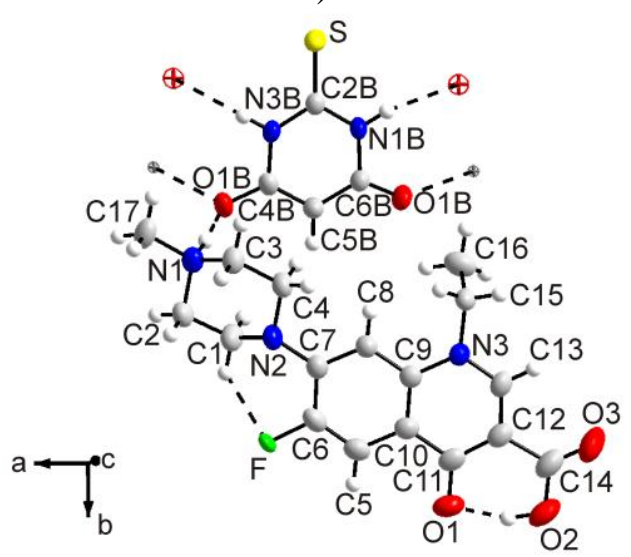

b)

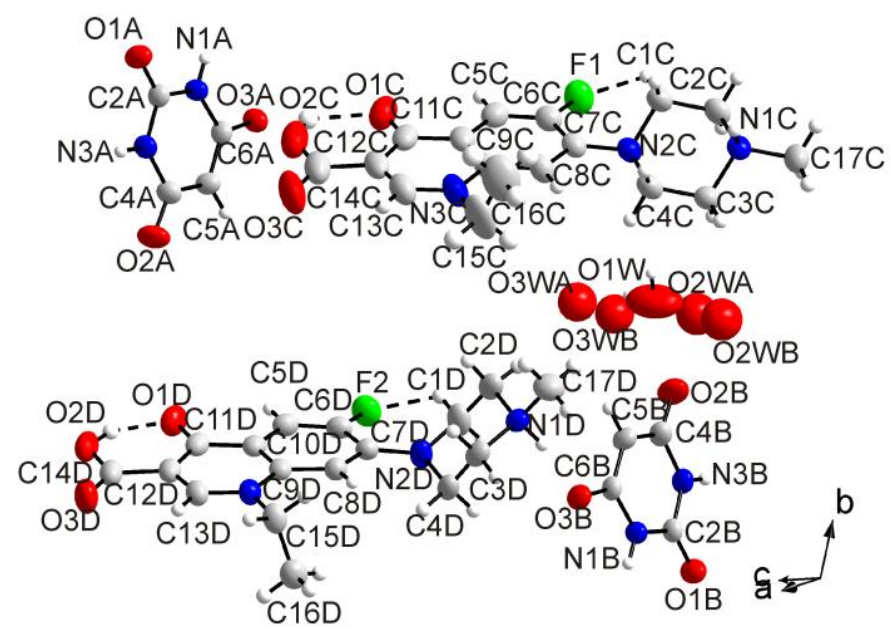

c)

Figure 2. The asymmetric unit of the $\mathrm{PefH}_{2}(\mathrm{Htba}) \cdot 3 \mathrm{H}_{2} \mathrm{O}$ (1) (a), $\mathrm{PefH}_{2}(\mathrm{Htba})$ (b) and $\left(\mathrm{PefH}_{2}\right)_{2}(\mathrm{Hba})_{2} \cdot 2.56 \mathrm{H}_{2} \mathrm{O}$ (3) (c) unit cell. All atoms in the asymmetric unit are labeled. The neighboring symmetry-generated atoms are represented by principal ellipses with an individual color. The bonds linking asymmetric unit atoms with the symmetry-generated atoms and intermolecular hydrogen bonds are represented by dashed lines. The ellipsoids are drawn at the $50 \%$ probability level, except for the hydrogen atoms represented by spheres. 


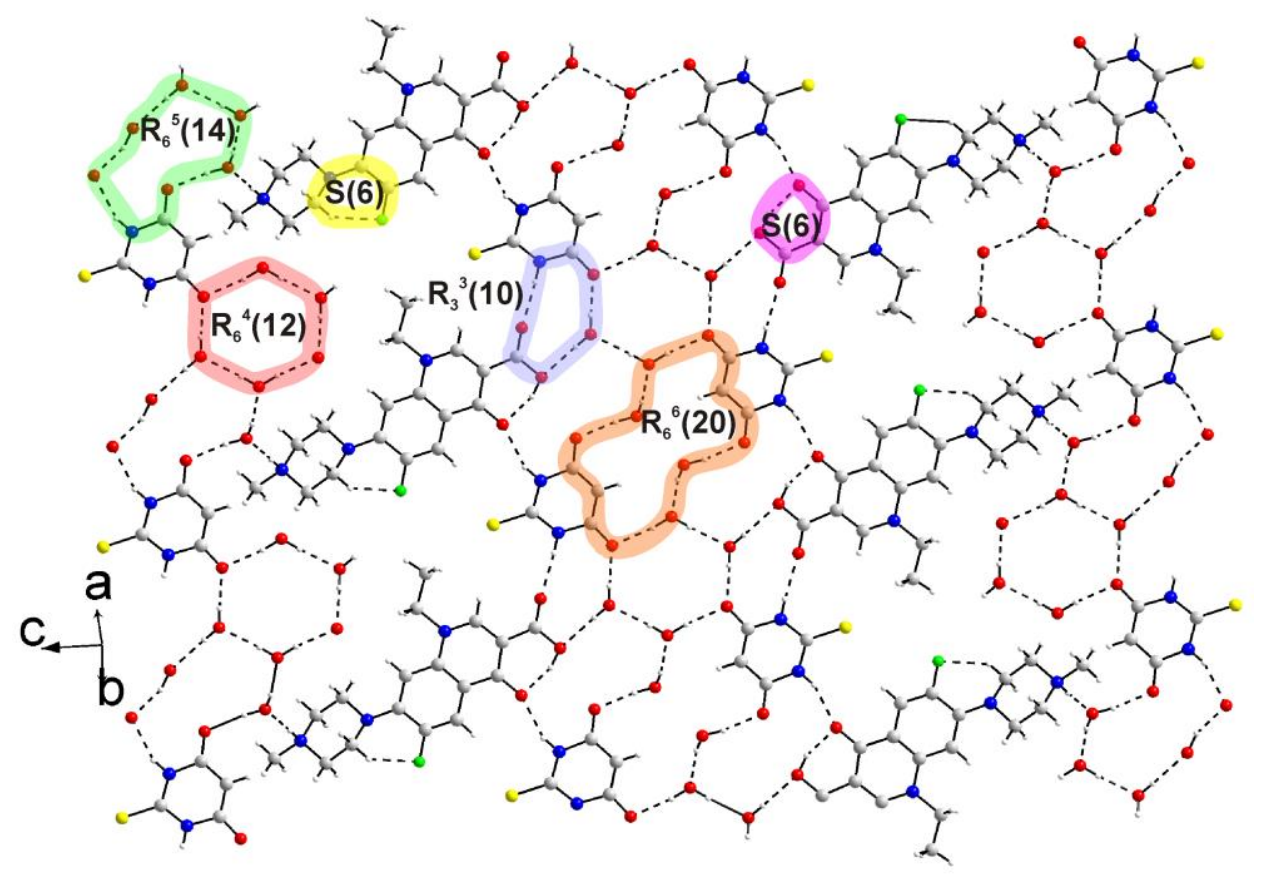

a)

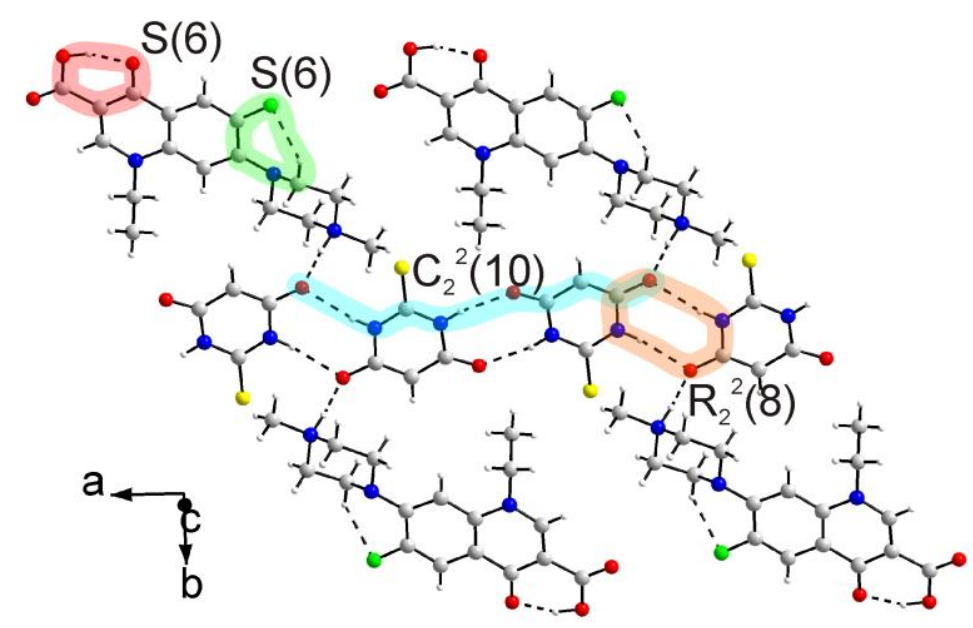

b)

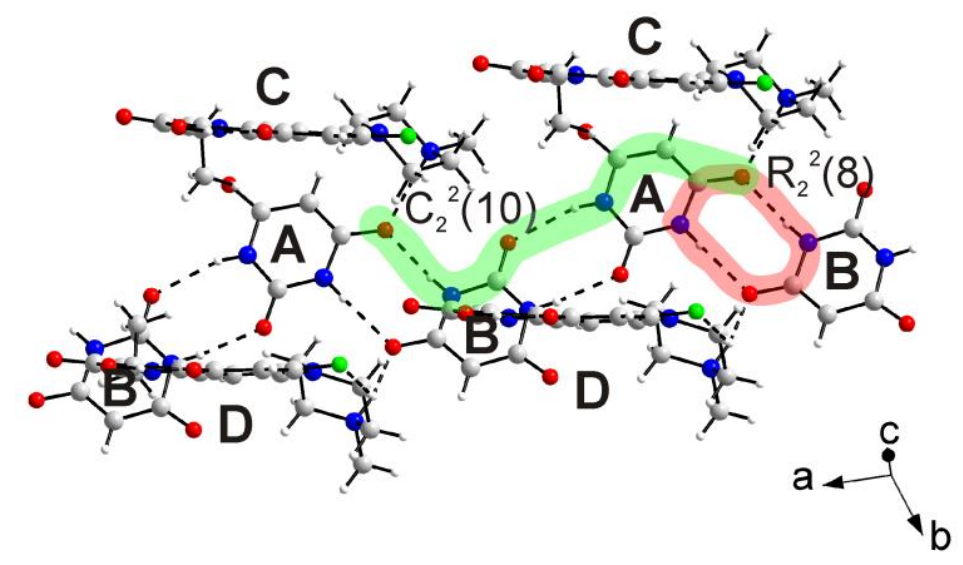

c)

Figure 3. Hydrogen bonding in $\mathbf{1}$ (a), 2 (b) and $\mathbf{3}$ (c). The H-bonds are marked by dashed lines, the $\mathrm{H}$-bond motifs are marked by circles. Different $\mathrm{Hba}^{-}$ions are marked by A, B labels and $\mathrm{PefH}_{2}{ }^{+}$ions are marked by $\mathrm{C}, \mathrm{D}$ labels in (3) (c). 